\title{
LA DIVERSIFICACIÓN DE LA OFERTA TURÍSTICA COMO ALTERNATIVA PARA MINIMIZAR LA ESTACIONALIDAD: EL CASO DE LOS EVENTOS EN BALNEÁRIO CAMBORIÚ (SANTA CATARINA, BRASIL)
}

\author{
Fabiana Calçada de Lamare Leitel
}

Instituto Federal de Santa Catarina. Santa Catarina. Brasil.

\section{RESUMEN}

El artículo analiza la diversificación de la oferta turística con la realización de eventos cómo una alternativa para reducir la estacionalidad. La ciudad de estudio es Balneário Camboriú, en el estado de Santa Catarina, Brasil. El enfoque de la investigación es bibliográfico. El marco teórico aborda el concepto de estacionalidad y el caso del Balneário Camboriú a partir de un enfoque histórico de la estructuración de la actividad turística en la ciudad y la identificación de los eventos como alternativa de diversificación de la oferta turística.

Palabras clave: Estacionalidad turística, Diversificación, Oferta Turística, Eventos, Balneário Camboriú.

Diversification of the tourist offer as alternative to minimize the season: the case of events in Balneário Camboriú (Santa Catarina, Brazil)

\section{ABSTRACT}

This article analyzes the diversification of tourism through the organization of events as an alternative to minimize seasonality. The city studied is Camboriú, in Santa Catarina,

Recibido: 28 de mayo de 2015

Devuelto para su revisión: 8 de diciembre de 2015

Aceptado: 2 de febrero de 2016

Instituto Federal de Santa Catarina. Campus Florianópolis Continente. Rua 14 de julho, 150. Florianópolis. SANTA CATARINA (Brasil).E-mail: fabianac@ifsc.edu.br

1 Doctorado en Geografía. Universidade Federal do Paraná, Curitiba, Brasil. Beca de estudios CAPES/ PDSE n ${ }^{\circ}$ 5185/2014-09 
Brazil. The focus of the research is literature. The theory introduces the concept of seasonality and the case of Balneário Camboriú from the viewpoint of the structure of tourism in the city and identification of events as an alternative to diversify the tourist offer.

Keywords: Seasonality, Diversification, Tourist Offer, Events, Balneário Camboriú.

\section{INTRODUCCIÓN}

Las actividades humanas están en general condicionadas por la estacionalidad. Es en un contexto de irregularidades que podemos encajar el comportamiento de los individuos; incluido el turismo. Sin embargo, la estacionalidad no implica de manera uniforme a todos los sectores de la economía, por lo que es importante entender sus orígenes, las causas y los impactos específicos de concentración estacional y su relación con la oferta y la demanda.

El tema de estudio de esta investigación es analizar cómo la ciudad de Balneário Camboriú está desarrollando el segmento de eventos como una alternativa para ayudar a minimizar la estacionalidad turística. La ciudad, con una superficie de $46 \mathrm{~km}^{2}$, está situada en el litoral centro-norte del estado de Santa Catarina, sur de Brasil y tiene una población de 124.557 (IBGE, 2014). La ciudad es considerada por el Ministerio del Turismo brasileño (MTur) uno de los tres destinos turísticos inductores ${ }^{2}$ en el estado de Santa Catarina. Es un destino de sol y playa consolidado para los turistas nacionales y extranjeros. Presenta una amplia oferta hotelera, con 120 hoteles y hostales y un total aproximado de 18 mil camas, según la Oficina de Turismo de la ciudad (SECTURBC, 2014). Además se caracteriza por tener su economía concentrada principalmente en el sector de los servicios (SECTURBC, 2014). De acuerdo con Pelizzoni (2004) y Canani (2001) la emancipación política impulsó la realización de proyectos específicos y de negocios para el sector del turismo.

La ubicación geográfica de la ciudad posibilita el acceso a otros destinos turísticos del estado, como Blumenau, Joinvile, Brusque, Bombinhas, Nova Trento, Florianópolis, caracterizados por la proximidad con la carretera nacional BR 101, el principal eje de conexión entre las ciudades en un radio de $50 \mathrm{~km}$.

La emancipación política de Balneário Camboriú fue el 20 de julio de 1964 por la ley estatal $n^{\circ} 960$ del mismo año (Borba Correa, 1985) y su proceso de urbanización ha alcanzado un índice de concentración demográfica de 2.337,73 hab/km² (IBGE, 2014). Con el clima templado subtropical, la temperatura media anual de Balneário Camboriú es de $25^{\circ}$ Celsius. El relieve está formado por superficies planas y colinas con vegetación predominante de Mata Atlántica y por los ecosistemas asociados. La transformación de la estructura original de la ciudad se puede apreciar en el paisaje debido a la presencia de

2 El programa "65 Destinos Indutores" tiene como objetivo definir los parámetros para evaluar el grado de desarrollo y preparar un plan de acción para los 65 destinos inductores del desarrollo turístico definidos por el Ministerio de Turismo para lograr la competitividad a nivel mundial. Su primera edición fue en el año de 2008 (Estudo de Competitividade dos 65 Destinos Indutores do Desenvolvimento Turístico Regional, Ministério do Turismo, Brasil, 2008). 
numerosos edificios en la línea de la playa, que influyó decisivamente en la configuración de su trazado urbano caracterizado por la verticalidad (Silva, 2002). La figura 2 muestra la configuración de los edificios que reflejan la preferencia y la valorización de las áreas próximas al mar para la construcción en Balneário Camboriú.

\section{UBICACIÓN DE BALNEÁRIO CAMBORIÚ, SANTA CATARINA, BRASIL}

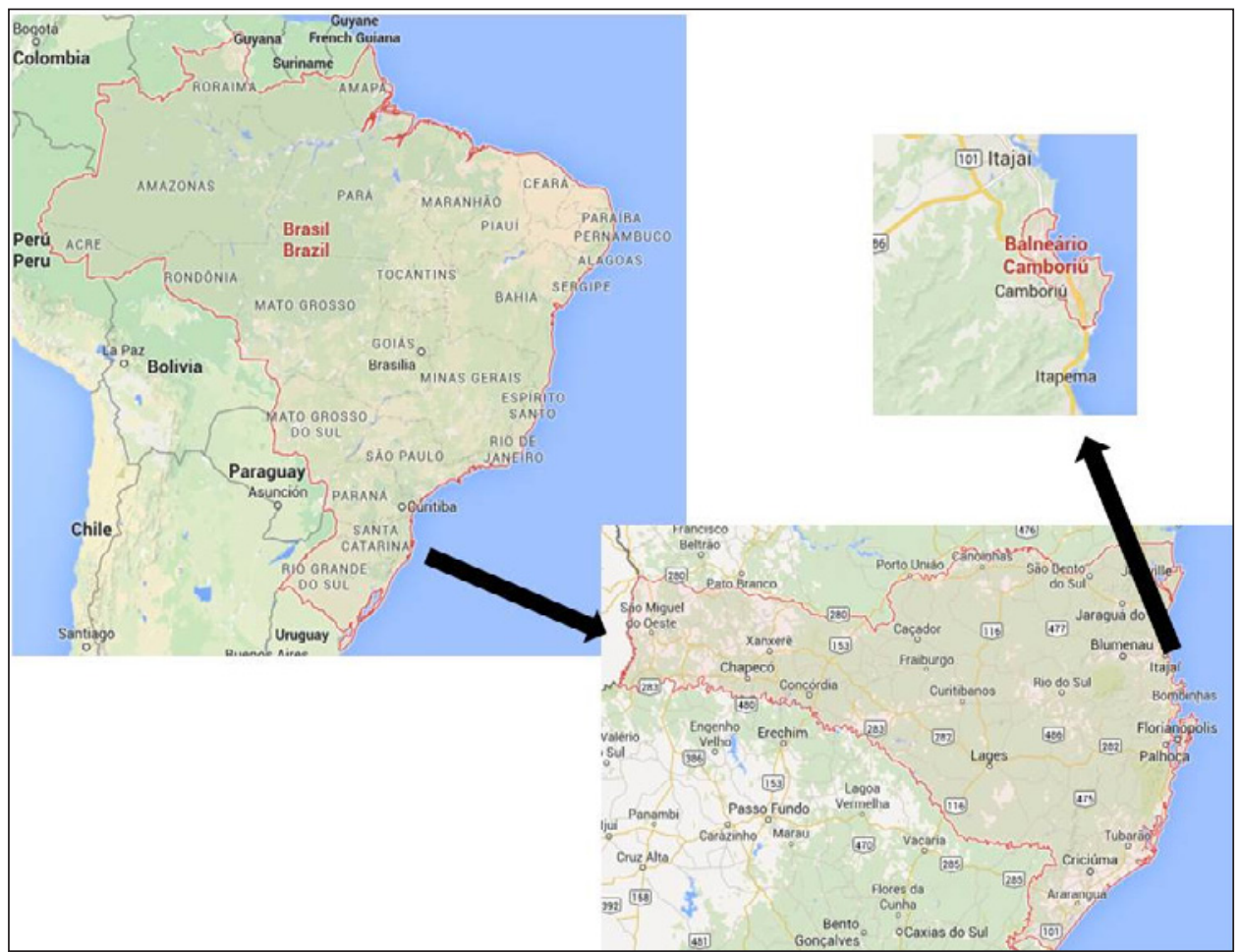

Fuente: Google Maps (2015).

El objetivo del artículo es estudiar la estrategia de diversificación de la oferta turística a través de los eventos en Balneário Camboriú cómo una alternativa para minimizar la estacionalidad. El enfoque de la investigación es bibliográfico y se han utilizado los datos estadísticos disponibles de los organismos oficiales. Así, el análisis se ha apoyado en la información proporcionada por la Oficina de Turismo de la ciudad y el Ministerio de Turismo brasileño

El artículo se estructura en base a los siguientes apartados: el marco teórico que aborda el concepto de estacionalidad, a continuación se enmarca y describe el caso de Balneário Camboriú, con un repaso histórico de la estructuración de la actividad turística en la ciudad y su ubicación en la regionalización turística de Santa Catarina así como las relaciones con las ciudades cercanas, para tras ello identificar la diversificación de los segmentos 
turísticos como estrategias adoptadas para minimizar la estacionalidad. Se presenta también un apartado específico que muestra los eventos que recientemente se desarrollan en la ciudad y finalmente se recogen las conclusiones de la investigación.

\section{Figura 2 \\ BALNEÁRIO CAMBORIÚ - PLAYA CENTRAL}



Fuente: Skalee y Reis (2008).

\section{MARCO TEÓRICO}

Entendemos que el turismo está influido por variables económicas, socio-culturales, políticas y ambientales y las consecuencias de la actividad turística pueden ser tanto positivas como negativas. La propia complejidad para definir la demanda turística como concepto requiere un análisis de los factores que condicionan la decisión de viajar a un lugar (Sancho, 1998). Sin embargo, tradicionalmente la planificación de la actividad turística se ha orientado mucho más a las demandas de los turistas mientras que la valoración del bienestar de los residentes se ha tenido menos en cuenta y ello cuestiona el éxito de las inversiones turísticas a largo plazo (Sancho, 1998). En esta línea, "la planificación debe garantizar un desarrollo integrado del turismo en la comunidad receptora, asegurando la satisfacción de las necesidades de los turistas, pero maximizando el bienestar de los residentes" (Sancho, 1998:239).

Sobre los datos del turismo en Brasil, aunque las estadísticas no son excelsas, presen$\tan$ un crecimiento constante de turistas. Entre los años 2010 y 2014 hubo un aumento de aproximadamente $20 \%$ en el número de turistas que llegó a Brasil ${ }^{3}$ (MTur, 2015).

Los destinos de sol y playa ocupan un lugar preferente para los turistas en Brasil. De acuerdo con el Ministerio do Turismo (MTur, 2013), entre los veinte destinos más buscados, doce son destinos litorales (Salvador, Recife, Fortaleza, Rio de Janeiro, Búzios, Angra dos Reis, Macaé, Parati, Vitória, Florianópolis, Balneário Camboriú e Bombinhas).

3 Año 2010 - 5.161.379 turistas / Año $2014-6.200 .000$ turistas (Mtur, 2015) 
Entre los turistas que viajan a Brasil por motivos de ocio, el 60,2\% busca el turismo de sol y playa y Balneário Camboriú ocupa la quinta posición entre los destinos litorales más visitados (MTur, 2011). Teniendo en cuenta que los tres primeros puestos están ocupados por Rio de Janeiro, Florianópolis y Salvador que no son destinos únicamente de sol y playa, sino también destinos de negocios; Balneário Camboriú es el segundo destino de sol y playa de Brasil (Soares, 2012; MTur, 2011).

Según Vera Rebollo et al (1997) y Ayala, Martin y Masique (2003), el turismo de Sol y Playa es responsable de generar un mayor flujo de turistas a escala internacional. Eso implica que, la mayor afluencia de turistas a las playas, comporta el incremento de la demanda de servicios en relación al alojamiento, ocio, compras, transporte, y otros con el objetivo de satisfacer las necesidades de la estancia en la playa (Ramos, 2009).

Además, el turismo de sol y playa se origina estimulado por diferentes cambios culturales, el desarrollo del transporte y las nuevas formas de comercialización con las agencias de viajes, los paquetes turísticos entre otros (Soares, 2012). El turismo de sol y playa, ha mostrado cambios estructurales en lo que respecta a la necesidad de crear estrategias de desarrollo que permitan a los destinos adaptarse a los cambios y seguir siendo competitivos (Santos Pavón y Tabales Fernández, 2010). Este es el caso de algunos de los destinos considerados consolidados, como Balneário Camboriú, que requiere un proceso de reestructuración con el objetivo de adaptarse a las nuevas exigencias sociales y económicas para su mantenimiento. (Vera Rebollo y Baños, 2010; Valls, 2004).

La estacionalidad de la oferta turística durante el año ${ }^{4}$ por razones climáticas se presenta como una de las principales características del mercado turístico (Lage y Milone, 1998). Frente a la estacionalidad cabe aportar estrategias de diversificación del producto sol y playa. En la literatura académica, la estacionalidad es uno de los aspectos más problemáticos del turismo, estudiado por autores como Baron (1975); Allcock (1989); Butler (1994; 2001), Ruschmann (1997); Baum y Lundtorp (2001) y Koenig y Bischoff (2004). Uno de los primeros investigadores en abordar la comprensión del concepto de la estacionalidad fue Baron (1975), indicando que la estacionalidad es la concentración de la demanda que se celebra todos los años en un intervalo de tiempo y con la misma magnitud. Butler (1994: 332) aporta la siguiente definición para el concepto:

un desequilibrio de tiempo en el fenómeno del turismo, que se puede expresar en dimensiones de el número de visitantes, el gasto, el tráfico en las carreteras y otros medios de transporte, el empleo y los ingresos en las atracciones.

Y en este sentido, la estacionalidad es la concentración de las actividades turísticas en el espacio y el tiempo (Ruschmann, 1997). En general, la comprensión de la estacionalidad enfoca conceptos tales como la concentración del turismo en determinados períodos del año, la concentración de las actividades, el uso y la saturación de los recursos. Además, la estacionalidad comporta picos en la prestación de servicios y en la presencia de turistas.

4 El verano en el hemisferio sur es opuesto al verano en el hemisferio norte. Así, el verano en Brasil empieza en el mes de diciembre y termina en marzo, mientras en el hemisferio norte es invierno. 
Son escasos los destinos que no presentan estacionalidad de la demanda, de modo que los actores públicos y privados se afanan en utilizar estrategias que permitan reducir al mínimo los efectos negativos (Baron, 1975; Butler, 2001). Así, “el turismo planificado y ordenado adecuadamente es una actividad que puede ayudar a las comunidades a reducir al mínimo los impactos negativos resultantes del turismo estacional» (Scheuer, 2011: 291).

Los factores que explican la concentración de los flujos turísticos y la estacionalidad, varían según del características del destino específico, como la ubicación geográfica, el origen de los turistas, el sector turístico (sol y playa, rural, cultural, etc.), las infraestructuras, los servicios y el atractivo de los recursos. Uno de los principales factores de la estacionalidad es el clima que existe independientemente de cualquier operación turística. Sin embargo, el factor climático se convierte en recurso turístico en el momento que se valoriza para la demanda turística (Ramís y Llinás, 2014).

Para autores como Neves, Cruz y Correa (2007) una de las soluciones para minimizar la estacionalidad es a través de la diversificación de la oferta turística que permita el flujo de personas durante la mayor parte del año, así como el desarrollo de productos turísticos complementarios a la estacionalidad. Otra solución es la identificación de nuevos segmentos de mercado para atraer los turistas al destino fuera de la temporada alta, tales como la creación de eventos (música, deportes, arte, cultura, etc.) y el desarrollo de nuevos productos turísticos que se promocionen en temporada baja (Butler, 1994; Baum y Hagen, 1999). Por ello, las medidas de gestión para minimizar la estacionalidad de un destino no deben ser analizadas sólo en el propio destino. Se debe tener en cuenta todo el movimiento que se realiza en la consecución de este objetivo y así desarrollar planes de acción estratégicos para la desestacionalización del lugar. La adopción de estas medidas conduce a una mejor difusión de la oferta del destino durante todo el año, minimizando así la concentración en momentos de picos y mitigando los efectos negativos de la estacionalidad.

\section{EL CASO DE BALNEÁRIO CAMBORIÚ}

En este apartado se realiza una descripción del desarrollo reciente del turismo en la ciudad de Balneário Camboriú 5 .

A finales de la década de 1920 comienza el proceso de desarrollo de la localidad. En 1926, se construyen las primeras casas de veraneo pertenecientes a brasileños de origen alemán procedentes principalmente de Blumenau que también organizaran las primeras excursiones de fines de semana en Camboriú6 (Skalee y Reis, 2008; Soares, 2012). La ciudad ubicada en el interior de Santa Catarina se ha caracterizado por la tradicional presencia de inmigrantes alemanes y se conecta con el litoral, por las carreteras BR 470 o BR 486 y por la carretera estatal SC 412. La distancia entre las ciudades de Blumenau y Balneário

5 Para evitar equívocos, puntualizamos que Balneário Camboriú és un nombre propio, una referencia de localización en el litoral. En este caso no existe relación con balneários termales. A modo de ejemplo, todavía hay dos ciudades más en Santa Catarina con el nombre Balneário y que, también, son ciudades de la playa: Balneario Piçarras y Balneario Barra del Sur.

6 Actualmente Camboriú y Balneário Camboriú son ciudades distintas, aunque en el pasado eran una única ciudad. Balneário Camboriú pertencia a Camboriú y, antes de su emancipación se denominaba a la región Camboriú. 
Camboriú es de $62 \mathrm{~km}$, la facilidad de acceso y las características naturales de las playas de la localidad, explican las crecientes edificaciones de las residencias de veraneo. Borba Corrêa (1985) afirma que fueron los germano-brasileños los que realizaron la construcción de la infraestructura turística inicial, con los primeros hoteles y comercios. Esta inicial demanda estimuló el crecimiento de infraestructuras para la localidad y en 1928, se abrió el primer hotel (Borba Corrêa, 1985). Los turistas, provenían principalmente del sur de Brasil y buscaban un clima más cálido en el litoral ya que el invierno en el interior y en las montañas del sur de Brasil es muy riguroso.

En la década de los años 1940 existían ya 6 hoteles (Borba Corrêa 1985). En relación a las residencias, al final de la década de 1940 se construyeron cerca de 100 casas y en el año 1952, hay un avance con la construcción de 620 casas (Silveira Junior, 1952). En la década de 1950, comenzó el uso turístico de la ciudad, con la construcción del Hotel Fischer, el primer hotel de categoría superior (cuatro estrellas), aunque según la población local se consideró que era una locura construir un hotel en una zona de playa absolutamente desierta en aquellos años (Borba Corrêa, 1985). El proceso de construcción continuó y en la década de 1960 se construyó en Hotel Marambaia, uno de los más tradicionales de la ciudad y también comenzó a cambiar el perfil de los turistas, decantándose hacia un mayor poder adquisitivo (Borba Corrêa, 1985). Así, el uso turístico se intensifica a partir de 1970, con la integración de la región a la red urbana regional a través de la abertura de la carretera BR-101, en 1971, que conecta los tres estados del sur de Brasil y es la principal carretera de acceso a Balneário Camboriú. Esta vía permite la conexión entre el norte y sur del país, favoreciendo la llegada de turistas nacionales y del Mercosur; según Pellizzoni (2004), comienza así, la llegada de turistas provenientes principalmente del estado de Paraná y Rio Grande do Sul. Y más tarde, de los países vecinos como Argentina, Paraguay y Uruguay favorecidos por la apreciación de la moneda ${ }^{7}$. Así, Soares (2012) señala que hasta 1976 el parque hotelero tuvo un gran crecimiento con la llamada "invasión de los argentinos" y la edificación fue muy rápida y con escaso control de calidad.

Soares (2012), indica que el aumento de los turistas a partir de la década de los noventa, está relacionado con la devaluación de la moneda brasileña y la "dolarización" de la moneda argentina; hecho que aumentó el poder de compra de los argentinos y mermó el de los brasileños.

En la década de 1980, Canani (2001) constata la gran inversión inmobiliaria y de la industria hotelera. De acuerdo con datos proporcionados por el ayuntamiento de Balneário Camboriú (PMBC, 2014), entre los años 1980 y 1990 hubo un destacado aumento de la superficie construida en la ciudad con un pico en 1988 que alcanzó 591,443.19 m². Esta expansión tiene como repercusión el incremento de los servicios, tales como restauración, compras y ocio $^{8}$. En la década de los noventa ha continuado este crecimiento y ello ha

7 La apreciación de la moneda Argentina y Uruguaya en comparación con la moneda brasileña aumentó el poder adquisitivo de los argentinos y uruguayos y fomentó el turismo a Brasil porque se identifico como uno de los destinos preferentes de sus vacaciones.

8 En 2010 (SEBRAE, 2010), Balneário Camboriú tenía 292 establecimientos de restaurantes y otros establecimientos de alimentación y bebida. Según la oficina de turismo de la ciudad, son 293 estabelecimientos en este sector (SECTURBC, 2010). 
ido acompañado por el crecimiento de la población de la ciudad que en 1970 tenía 10.180 habitantes, llegando a 40.308 en 1991, y en 2011, ya ha alcanzado los 108. 107 habitantes con una población estimada de 124.557 habitantes en 2014 (IBGE, 2014).

Para satisfacer la demanda de la población turística, la estructura de Balneário Camboriú ha sufrido diversas transformaciones a lo largo de las últimas cuatro décadas centrados en los cambios en la red de carreteras, creación de infraestructuras, implantación de nuevas concentraciones de vivienda y alojamiento, y promoción de centros comerciales, de salud y ocio (Skalle y Reis, 2008:15). Las siguientes imágenes muestran el crecimiento de la ciudad en diferentes etapas y destacan la paulatina concentración de construcciones en el espacio de playa, muestra del desarrollo turístico de la ciudad.

Figura 3

AVENIDA ATLÂNTICA EN LA DÉCADA DE 1960

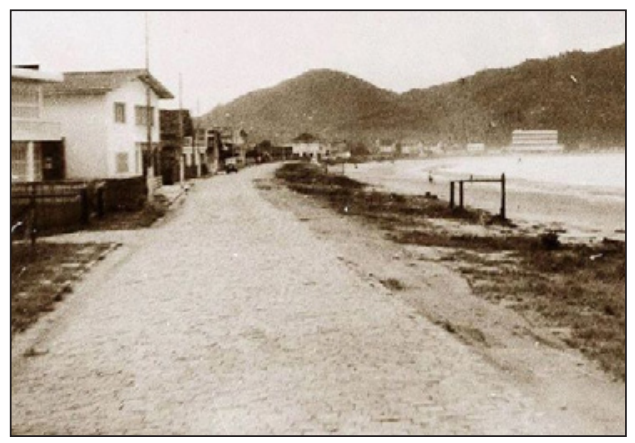

Fuente: Clube dos Entas Itajaí (2015).

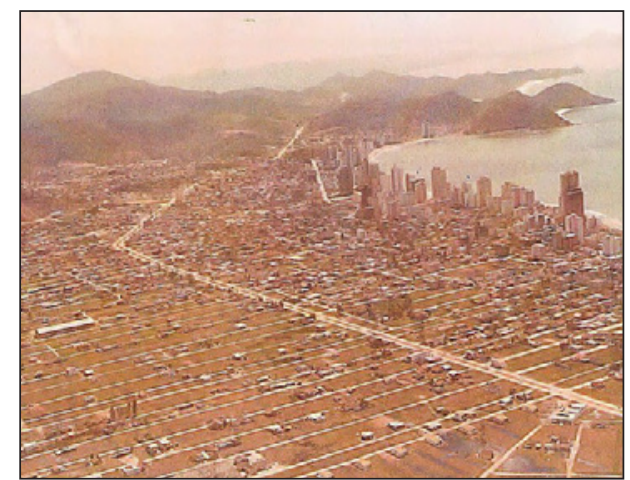

Fuente: Clube dos Entas Itajaí (2015).

\section{Figura 4 \\ VISTA PANORÁMICA \\ DÉCADA DE 1970}

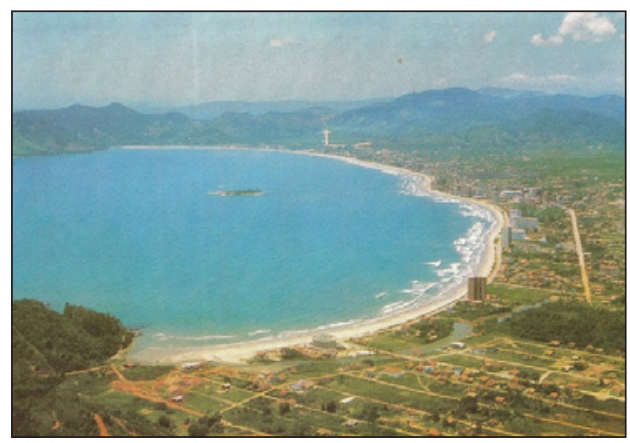

Fuente: Clube dos Entas Itajaí (2015).

\section{Figura 6 VISTA PANORÁMICA - DÉCADA 2000}

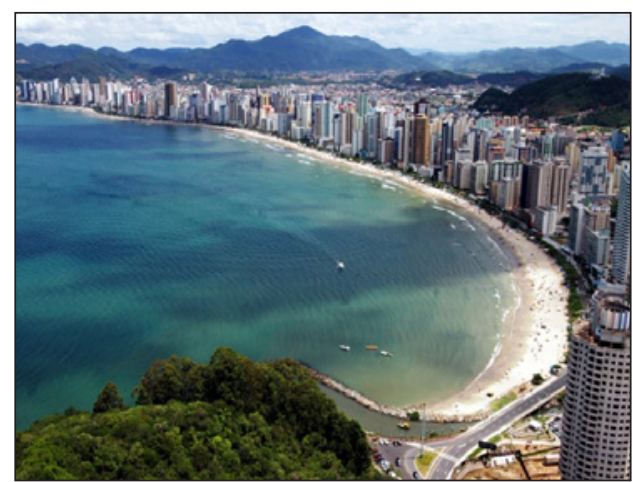

Fuente: Clube dos Entas Itajaí (2015). 
Las siguientes imágenes son de la "Terceira Avenida", una avenida interna de la ciudad, y muestran el incremento de infraestructura comparando dos momentos históricos de la ciudad: la década de 1970 y en 2014.

Figura 7

TERCEIRA AVENIDA DÉCADA DE 1970

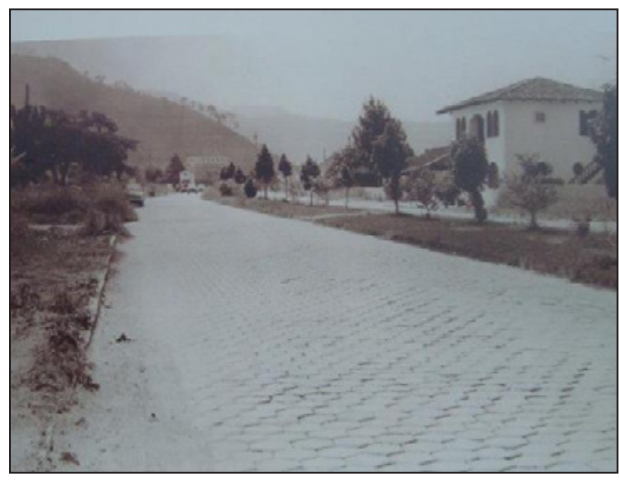

Fuente: Clube dos Entas Itajaí (2015)

\section{Figura 8 \\ TERCEIRA AVENIDA, 2014}

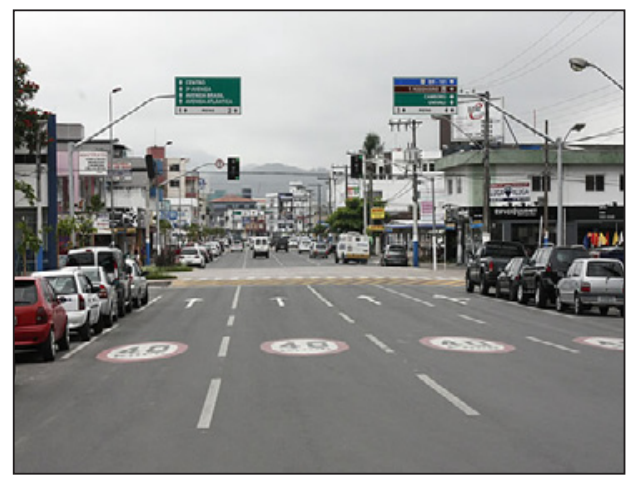

Fuente: Clube dos Entas Itajaí (2015)

A finales de la década de 1980, Balneário Camboriú empieza a trabajar con el turismo de la tercera edad como un intento de desestacionalizar y mejorar la llegada de turistas en temporada baja (Starkee Lee, 1998) y a finales de la década de 1990, se implementan acciones de diversificación de la oferta del destino: con la construcción del Cristo Luz, el Parque Unipraias, la Marina Tedesco y nuevos centros comerciales (Soares, 2012).

El Parque Unipraias fue inaugurado en 1999 y consiste en un Parque en el Monte da Aguada con un teleférico que conecta la Playa Central con la Playa de Laranjeiras. En lo alto del monte, el parque ofrece actividades de recreación, restauración y miradores desde donde divisar la ciudad. El Cristo Luz se construyó en 1997 en el alto del Monte de la Cruz. El complejo posee restaurantes, un museo y un mirador. Y La Marina Tedesco inaugurada en 2006, con 500 plazas para muelle de embarcaciones y donde también se realizan eventos.

\subsection{Balneário Camboriú y la regionalización Turística del estado de Santa Catarina}

Actualmente, en la regionalización turística del estado de Santa Catarina, Balneário Camboriú se encuentra en la región Costa Verde y Mar, litoral centro-sur del estado (Figura 9). Se sitúa en la misma región, las ciudades de Balneário Piçarras, Bombinhas, Camboriú, Ilhota, Itajaí, Itapema, Luis Alves, Navegantes y Penha. Los ejecutores del Programa de Regionalización del Turismo en Santa Catarina son la Santa Catarina Turismo SA (SANTUR, 2015) y el Departamento de Turismo, Cultura y Deporte (SOL, 
2015) y trabajan en proyectos con la siguiente regionalización: Sierra de Santa Catarina, Camino de Cañones, Costa Verde y el mar, los encantos del Sur, Camino de los Príncipes, Valle Europeo, Sendero Fronteriza, Gran Oeste, Valle del Contestado y la Gran Florianópolis.

El principal criterio para esta regionalización, es la caracterización de ciudades costeras que se identifiquen con la forma de vida de la costa. El Plan de Regionalización del Turismo prevé el aumento de la competitividad de los destinos inductores y la comercialización de circuitos turísticos integrados.

\section{Figura 9 \\ REGIONES TURÍSTICAS DE SANTA CATARINA}

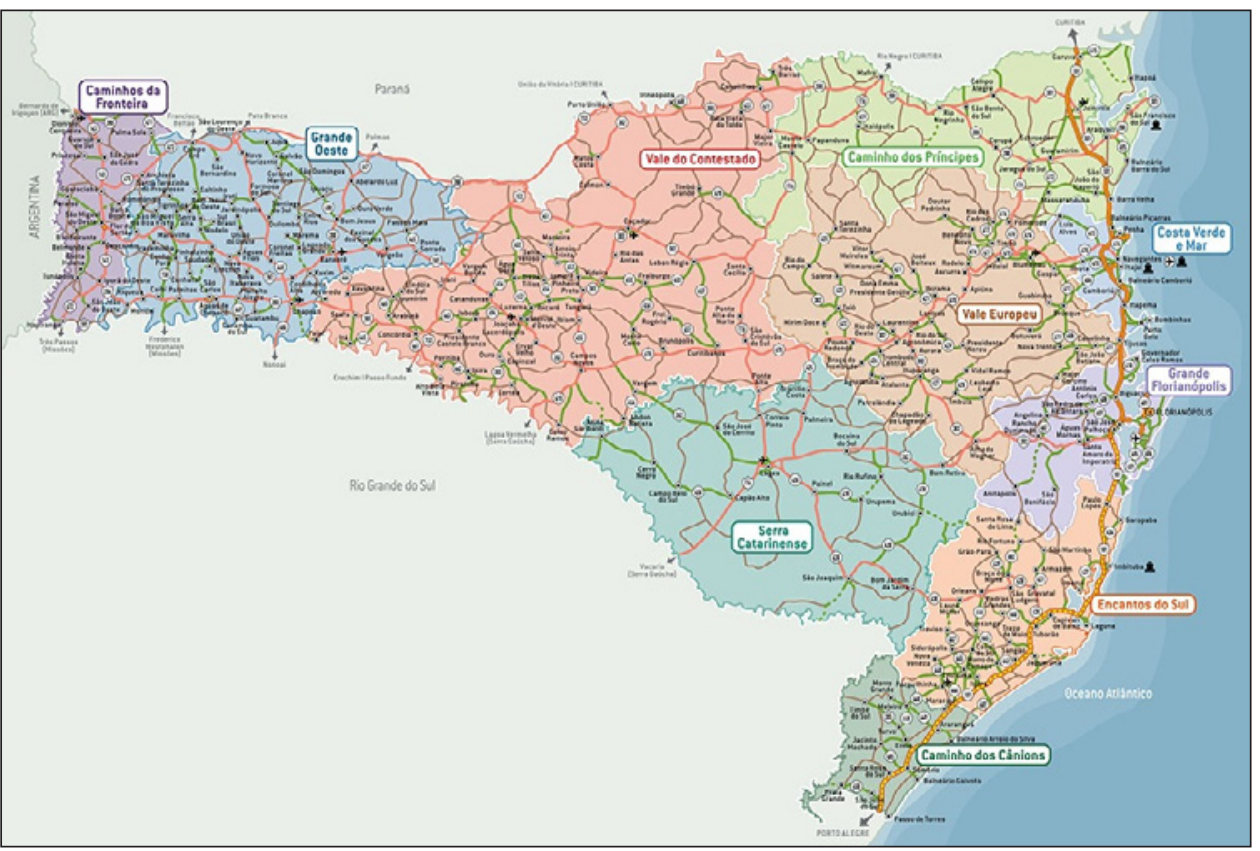

Fuente: SANTUR (2014).

La diferenciación de las regiones es también un proceso para la diversificación de la oferta, dado que es una forma de generar identidad, fortalecer la imagen del destino y, en consecuencia atraer a los distintos turistas en base a una oferta amplia y variada. En el caso del turismo, la diferenciación se refiere a los elementos distintivos del territorio en los cuales la oferta turística y su respectiva promoción deben apoyarse (Inostrosa y Cànoves, 2014).

Los destinos turísticos deben potenciar sus diferencias en relación a otros destinos para desarrollar estrategias de atracción de turistas e inversiones que permitan el desarrollo turístico (Díez, 2012). Así, en base a Inostroza y Cànoves, (2014:120) “Las singularidades del territorio aportan ventajas comparativas, que en el caso del turismo están 
constituidas por los recursos endógenos del destino, como son los recursos naturales y culturales, su ubicación geográfica en relación a los principales mercados turísticos y el clima, entre otros".

Actualmente, Balneário Camboriú es uno de los principales centros turísticos en el sur de Brasil. El Ministerio de Turismo (MTur) lo seleccionó como uno de los tres destinos inductores turísticos en el estado de Santa Catarina, sur de Brasil. El programa de 65 destinos inductores del Ministerio de Turismo, tiene como objetivo definir los parámetros para evaluar el grado de desarrollo y preparar un plan de acción para los 65 destinos (MTur, 2008).

Sobre lo que Diez (2012) apuntó con la relación a otros destinos para desarrollar estrategias de atracción de turistas e inversiones que permitan el desarrollo turístico, Balneário Camboriú trabaja con el acercamiento con las ciudades vecinas, como una especie de asociación en el sector turístico. Por ejemplo, con las ciudades de Camboriú, Bombinhas y Itajaí. Así, no sólo el principal segmento específico de Balneário Camboriú, sol y playa, es el motivador para visitar la ciudad.

La imagen siguiente muestra la localización de dichas ciudades en relación a Balneário Camboriú con una breve explicación de los principales segmentos turísticos de cada ciudad y su relación con el turismo de Balneário Camboriú.

\section{Figura 10 \\ CERCANÍAS DE BALNEÁRIO CAMBORIÚ}

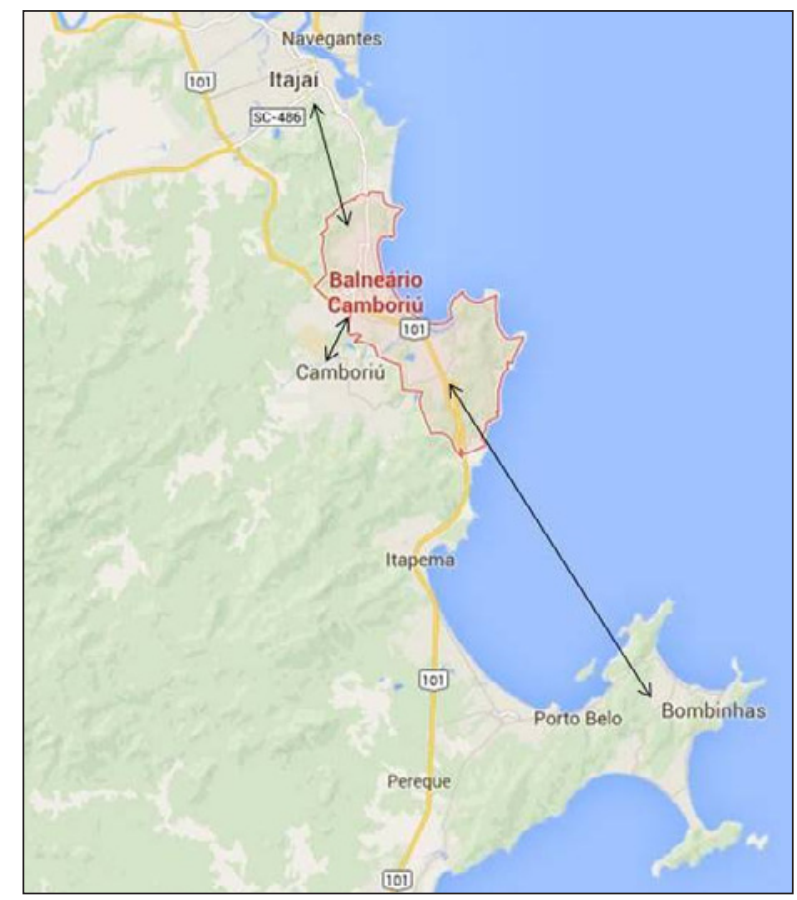

Fuente: elaboración propia a partir del Google Maps (2015). 
La ciudad de Camboriú es la frontera noreste de Balneário Camboriú y está situada en el interior del estado. La ciudad tiene una superficie de $211,60 \mathrm{~km}^{2}$, siendo el medio ambiente urbano sólo una cuarta parte de la superficie total del municipio y el otro 3/4, el medio ambiente rural. (Prefeitura de Camboriú, 2015). Esta configuración explica la vocación al principal sector turístico de la ciudad: el Turismo Rural. La ciudad ofrece espacios para los deportes al aire libre, rutas de senderismo y cascadas, paseos a caballo, lagos de pesca y otras atracciones que explica la complementariedad de las actividades y la relación con Balneário Camboriú por la diversidad de actividades disponibles. Así, el turista puede pasar el día en un entorno natural en las zonas rurales y volver a Balneário Camboriú para alojarse en hoteles y hostales rodeados de tiendas, restaurantes de infraestructura y servicios. Este escenario presenta la complementariedad entre dos segmentos distintos y la posibilidad de atraer a los turistas con diferentes perfiles y requisitos.

Bombinhas está lejos $39 \mathrm{~km}$ de Balneário Camboriú y es también una ciudad de sol y playa. Las ciudades difieren, entre otras cosas, por sus configuraciones territoriales como la formación peninsular de Bombinhas y su pequeña población de sólo 16.897 (IBGE, 2014). Además, el $60 \%$ del territorio total del municipio se encuentra en las cercanías de una reserva marina, la Reserva Marina del Arvoredo, lo que hace que las aguas de sus playas sean transparentes, que albergan diferentes especies y esto da a Bombinhas el título de Capital del Buceo Ecológico de Santa Catarina. Además de buceo, en Bombinhas también es posible practicar senderismo, canotaje, escalada, surf, entre otros deportes de naturaleza y aventura (Prefeitura Municipal Bombinhas, 2015). El perfil menos masificado, centrado en la naturaleza y el turismo deportivo es la diferencia que hace la relación con Balneário Camboriú y fortalece la colaboración para complementar la actividad turística con segmentos distintos.

Otra ciudad que trabaja la relación con Balneário Camboriú para atraer a los turistas por la diversificación de los segmentos es Itajaí. Con la conexión por carretera BR 101 o las carreteras Oswaldo Reis y Carretera de la Rainha, Itajaí es sólo 15 km de Balneário Camboriú. El sector del turismo que justifica la complementariedad entre los municipios es: las playas propicias para el surf, la infraestructura para las fiestas que suceda durante el día y por la noche en la temporada de verano y el turismo histórico y de negocios. Además, Itajaí es una ciudad con 201.557 habitantes (IBGE, 2014) y se caracteriza por contar con actividades relacionadas con la logística, la construcción, las actividades industriales y el complejo portuario con el segundo mayor movimiento de contenedores de Brasil (PREFEITURA MUNICIPAL ITAJAÍ, 2015). Este perfil de la actividad económica es uno de los segmentos que complementa la actividad turística de Balneário Camboriú y fortalece la relación entre los municipios por la distinción de segmentos y, como ya se mencionó, Balneário Camboriú tiene una amplia gama de instalaciones, servicios de apoyo al turismo y gran oferta de actividades de ocio.

Los datos de la demanda turística, proporcionados la Oficina de Turismo de Balneário Camboriú (SECTURBC, 2015) para el período de temporada alta de enero y febrero de 2012. Durante este período, indican que un total de 817.418 turistas visitaron la ciudad y la estimación de ingresos para el mismo período fue de aproximadamente 2 billones de Euros. 
Sobre el flujo mensual de turistas en Balneário Camboriú, el grafico siguiente refleja que los meses de enero, febrero y diciembre, que son los meses de de vacaciones, son los de mayor afluencia de turistas. Además, julio se ha destacado, posiblemente también por ser un mes de vacaciones escolares.

Otro punto a destacar es el mes de octubre, debido a que es el «mes del niño» y el "mes de las fiestas" en el estado de Santa Catarina9. Ambas celebraciones atraen turistas a Balneário Camboriú como destino de alojamiento. Durante el "mes de los niños" Balneário Camboriú se convierte en el destino dormitorio para los turistas que visitan el parque temático Beto Carrero World, en la ciudad de Penha, a 36 kilómetros. Sobre el "mes de las fiestas" en el estado de Santa Catarina, muchos turistas adoptan por alojarse en Balneário Camboriú para asistir a el Oktoberfest en Blumenau (a 62 kilometros), el Fenarreco em Brusque (a 42 kilometros), el Marejada en Itajaí (a 15 kilometros), entre otras fiestas de ciudades cercanas.

Además de este aumento mensual también es posible ver el aumento de turistas anuales. En 2011, el mes de febrero, tenía menos turistas en comparación con años anteriores. El mes de marzo, tuvo un aumento de turistas, y fue el mes del año con el mayor número de turistas, esta diferencia se debía a que el Carnaval de este año fue en marzo diferente de otros años.

Los «intervalos» para los meses de marzo, abril, mayo, junio y agosto, septiembre, octubre y noviembre son los meses de menor demanda de turismo en la ciudad. Esto se debe al hecho de que son los meses laborales del calendario brasileño y la ocurrencia de invierno en la región sur de Brasil durante junio, julio y agosto.

\section{Gráfico 1 \\ FLUJO MENSUAL DE TURISTAS - BALNEÁRIO CAMBORIÚ}

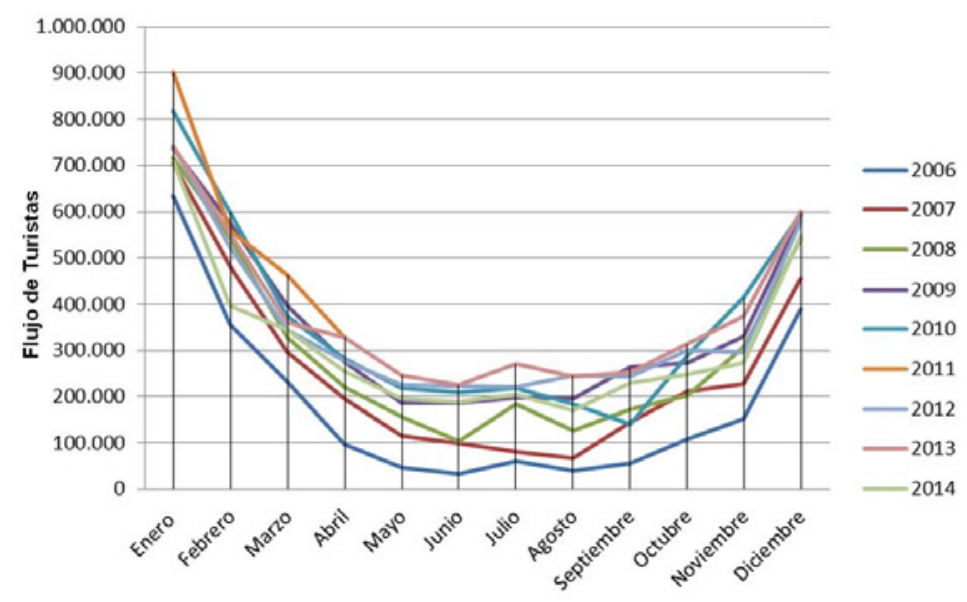

Fuente: elaboración propia a partir de los datos de la Secretaria de Turismo e Desenvolvimento Econômico (SECTURBC, 2014).

9 El mes de octubre se caracteriza por ser un mes en que ocurre las principales celebraciones típicas de diversas comunidades de inmigrantes en Santa Catarina. Son ejemplos: Alemanes en la ciudad de Blumenau y Brusque, Italianos en Nova Veneza y Portugueses en Itajaí. 
Los datos del gráfico 1 indican que la estacionalidad en la ciudad se caracteriza por, los meses de verano (excepto el mes de julio que son las vacaciones escolares). Como resultado, se observa que los "intervalos" para los meses que van de marzo a noviembre son los de menor demanda de turismo en la ciudad. Esta situación coincide con las tradicionales pautas de un lugar de sol y playa en donde la concentración de turistas es muy estacional, dejando desierta la ciudad el resto del año con los problemas de actividad económica que ello comporta. Ramís y Llinás (2014) presentan situación similar a estacionalidad climática de Balneário Camboriú con el caso de Mallorca, Islas Baleares, España. Según los autores, Mallorca viene definida por la importancia que tiene el turismo de sol y playa dentro de su modelo turístico predominante y, así como Balneário Camboriú, el óptimo climático para su desarrollo coincide con las vacaciones de verano (al revés de Mallorca, las vacaciones de verano en Brazil son en enero).

\subsection{Diversificación turística: los eventos}

Hemos visto que la estrategia de la regionalización comporta un intento de identificar la región y por tanto atraer turistas a la misma. Las estrategias más avanzadas proponen la diversificación de los segmentos turísticos y la mayor relación con otros municipios de la región para desarrollar actividades complementarias a la oferta sol y playa de Balneário Camboriú. Uno de los segmentos en el que está trabajando la ciudad es el de eventos, a fin de conseguir que la celebración de los mismos a lo largo del año pueda rebajar la estacionalidad turística que padece la ciudad y distribuir la afluencia de turistas a lo largo del año. La siguiente tabla muestra el tipo de eventos que se realizan a lo largo del año.

En los datos mensuales presentados en el gráfico 1 a cerca de lo flujo turístico y su relación con el calendario de eventos, se observa que entre los meses de abril y octubre son los meses que reciben el mayor número de eventos coincidiendo con los meses de menor flujo turístico.

Tabla 1

EVENTOS EN BALNEÁRIO CAMBORIÚ: AÑO 2015

\begin{tabular}{|c|c|c|}
\hline \multicolumn{3}{|r|}{ Año 2015} \\
\hline Mes & Dias & Eventos \\
\hline Enero & & 0 \\
\hline Febrero & & Carnaval de Balneário Camboriú \\
\hline Marzo & $\begin{array}{l}27 \text { a } 30 \\
27 \text { y } 28\end{array}$ & $\begin{array}{l}3^{\circ} \text { Maraca Beach Tennis } \\
\text { Torneio de Basquete Máster Feminino }\end{array}$ \\
\hline Abril & $\begin{array}{l}2 \text { a } 5 \\
17 \text { a } 20 \\
23 \text { a } 30 \\
30\end{array}$ & $\begin{array}{l}\text { Semana Santa y Páscoa } \\
\text { Encontro de Estudantes de Psicologia } \\
\text { Exposições de Esculturas } \\
\text { Meia Maratona de Balneário Camboriú }\end{array}$ \\
\hline
\end{tabular}




\begin{tabular}{|c|c|c|}
\hline Mayo & $\begin{array}{l}12 \text { a } 14 \\
25 \text { a } 04 / 06 \\
16 \text { a } 25 \\
\text { Todos el mes }\end{array}$ & $\begin{array}{l}\text { SC Trade Show } \\
5^{\circ} \text { CINERAMABC - Festival Internacional de Cinema em } \\
\text { Balneário Camboriú } \\
2^{\circ} \text { Mostra de Teatro } \\
\text { VI Congresso FIAPAM Intergeracional } \\
\end{array}$ \\
\hline Junio & $\begin{array}{l}29 / 05 \text { a } 04 / 06 \\
09 \text { a } 12 \\
17 \text { a } 20\end{array}$ & $\begin{array}{l}5^{\circ} \text { CINERAMABC - Festival Internacional de Cinema em } \\
\text { Balneário Camboriú } \\
\text { JICIT Jogos Escolares de Integração } \\
\text { V Festival da Canção }\end{array}$ \\
\hline Julio & $\begin{array}{l}04 \text { a } 07 \\
09 \text { a } 26 \\
10 \text { a } 17 \\
11 \\
11 \\
19 \text { y } 20 \\
20 \\
25\end{array}$ & $\begin{array}{l}\text { Encontro Internacional de Estudantes de Relações } \\
\text { Internacionais } \\
6^{\circ} \text { Festival Gastronômico Balneário Camboriú Saboroso } \\
\text { Jogos Estudantis de Balneário Camboriú } \\
\text { Feira Pedagógica } \\
\text { Cãominhada } \\
\text { Aniversário da cidade } \\
\text { Casamento Coletivo } \\
17^{\circ} \text { Encontro dos Amigos }\end{array}$ \\
\hline Agosto & $\begin{array}{l}18 \text { a } 21 \\
21 \text { a } 28 \\
22\end{array}$ & $\begin{array}{l}\text { JISAMA - Jogos de Integração } \\
\text { Semana das Diferenças } \\
\text { BC Prevenida }\end{array}$ \\
\hline Septiembre & $\begin{array}{l}01 \\
01 \text { a } 07 \\
22 \text { a } 26 \\
29\end{array}$ & $\begin{array}{l}\text { Caminhada da Paz } \\
8^{\circ} \text { Festival Náutico Marina Tedesco } \\
\text { Jogos JEBEQUINHO } \\
\text { Dia Internacional do Turismo }\end{array}$ \\
\hline Octubre & $\begin{array}{l}11 \text { y } 12 \\
17 \\
20 \text { a } 23\end{array}$ & $\begin{array}{l}\text { BC Criança } \\
\text { Outubro Rosa } \\
\text { JICIG Jogos de Integração }\end{array}$ \\
\hline Noviembre & $\begin{array}{l}14 \\
15\end{array}$ & $\begin{array}{l}\text { Novembro Azul } \\
\text { Abertura Brilhos de Natal }\end{array}$ \\
\hline Diciembre & $\begin{array}{l}05 \\
31\end{array}$ & $\begin{array}{l}\text { Abertura da Temporada } \\
\text { Reveillón Show }\end{array}$ \\
\hline
\end{tabular}

Fuente: elaboración propia a partir de los datos de SECTURBC (2015)

Para el año 2015, el programa proporcionado por la Secretaría de Turismo (SECTURBC), no tiene eventos para el mes de enero y sólo un evento para el mes de febrero, el Carnaval. La temporada alta y la demanda de las vacaciones de verano disfrutan de la oferta disponible y no requieren diferentes estrategias de atracción. Además, en febrero es el Carnaval, fiesta responsable de atraer turistas a la ciudad, tanto por sus atractivos naturales como para ir a las discotecas que promueven muchas fiestas en este período.

El mes de marzo registra dos eventos prolongados relacionados con los deportes. El primer es la tercera edición del "Maraca Beach Tennis Brasil". Ese deporte es como lo tradicional pero practicado en las arenas de la playa. De acurdo con la oficina de deporte de Balneário Camboriú, lo evento reunió a 350 atletas y es considerado lo más grande evento 
de este tipo de deporte (Fundação Municipal de Esporte de Balneário Camboriú, 2015). El otro evento es lo "Torneio de Basquete Master Feminino" (campeonato de baloncesto femenino). Ese evento fue una celebración a los 20 años de la Federación de Baloncesto de Santa Catarina y reunió cuatro equipes para la competición.

Los meses de abril y mayo, con un total de ocho eventos concentra el segmento de congresos, eventos académicos y el SC Trade Show. En abril, hay las celebraciones de la Semana Santa y Páscoa. Además, hay una exposición de esculturas de un artista de la ciudad, un evento de estudiantes y la "Meia Maratona de Balneário Camboriú" que en 2015 reunió más de 1800 participantes según datos de la oficina de Turismo de la ciudad.

En el mes de mayo lo destaque es para el evento SC Trade Show que es un evento señalado en el Índice Nacional de Competitividad Turística (MTur, 2013) como una práctica adoptada por el destino que tiene una conexión directa con el turismo y contribuye al desarrollo de la localidad. Este evento fue creado en 2008 y, de acuerdo con el Ministerio de Turismo, es una práctica promocional entre el trade del turismo de Santa Catarina que resulta beneficiosa para la ciudad como destino turístico. Fue desarrollado e implementado para promover el estado en todo Brasil, así como a otros países que forman parte del Mercosur y otros países de América Latina. La colaboración institucional con el trade del turismo reúne Balneário Camboriú, los otros municipios de la región de la Costa Verde y Mar y el gobierno del estado, a través de la Santa Catarina Turismo SA (SANTUR) y el Departamento de Turismo, Cultura y Deporte del Estado (SOL) (MTur, 2013).

Mayo todavía sucede dos eventos culturales: el $5^{\circ}$ CINERAMABC, lo "Festival Internacional de Cinema em Balneário Camboriú" y la $2^{\circ}$ "Mostra de Teatro". Lo Festival de Cinema ocurre en la ciudad con exibición de películas en pantallas montadas por algunas plazas de la ciudad y en una sala oficial con capacidad para 700 personas. Hay exibiciónes todos los días. Y la "Mostra de Teatro es una reunión de presentaciones de artistas locales y sus trabajos teatrales. En este evento hay también cursos relacionados al teatro que son ofrecidos a la comunidad. El ultimo evento en mayo es lo VI Congresso FIAPAM Intergeracional. Ese es un evento social que tiene como objetivo promocionar la integración de los membros de la familia de generaciones distintas y incentivar la creación de nuevas políticas sociales.

Tres acontecimientos suceden en junio, uno de ellos es la continuidad del Festival de Cine de Balneário Camboriú Internacional, que comenzó a finales de mayo, y que se encuentra en su quinta edición. La recurrencia de las ediciones de los eventos son una indicación de que esta acción es una opción para atraer a la demanda de las épocas del año que no sea la temporada alta de verano en el hemisferio sur (diciembre, enero y febrero). El otro evento es lo V Festival da Canção de Balneário Camboriú, promovido pela Fundação Cultural da ciudad con el objetivo de incentivar a divulgación de los cantores de la región. Y el tercero evento del mes de junio es un evento deportivo local de las escuelas: "JICIT Jogos Escolares de Integração".

En julio hay ocho eventos presentados en los datos de la oficina de turismo de la ciudad. Uno es la celebración del cumpleaños de la ciudad. Hay también eventos académicos, como la "Feira Pedagógica" de la Oficina de Educación y lo "Encontro Internacional de Estudantes de Relações Internacionais" promocionado por la Universidade do Vale do Itajaí. Sobre los deportes hay los "Jogos Estudantis de Balneário Camboriú" con la presencia 
de los estudiantes de escuelas públicas e privadas. Otros eventos importantes del mes de julio son la "Cãominhada", día en que las personas van a caminar juntas llevando a sus perros; lo "Casamento Coletivo", una fecha en que el ayuntamiento celebra las bodas de las parejas que quieren casarse de manera económica y; lo "Encontro dos Amigos". Ese evento se encuentra en su décimo séptimo año y es una celebración de mucho grupos de amigos que se reúnen en la playa central de la ciudad durante todo el día.

Lo evento más importante del mes de julio es lo " 6 Festival Gastronómico de Balneário Camboriú" que tiene como meta principal la divulgación de los restaurantes de la ciudad. Lo evento ocurre durante 15 días del mes de julio y su principal atractivo es la participación de muchos restaurantes de la ciudad con una opción de menú a precio fijo. En el año 2015 son 26 los restaurantes participantes. Según la Oficina de Turismo de Balneário Camboriú, en 2014 el Festival rompió el récord de ediciones anteriores con un total de 7.669 platos de comidas vendidos, lo que significa un incremento del 39\% en comparación con el evento del año de 2013 (SECTURBC, 2015). Además, hay una programación paralela con workshops de chefs de cocina brasileños y extranjeros para los interesados no solamente en la degustación. Este evento gastronómico se encuentra en su sexto año, lo que confirma la misma tendencia relacionada con el evento cinematográfico y la distribución de la demanda de la ciudad durante el año con la consiguiente minimización de la estacionalidad.

El mes de agosto y septiembre registraron juntos en 2015 siete eventos organizados durante eses meses. En agosto, son tres eventos: los "Jogos de Integração JISAMA", juegos disputados entre las escuelas de la ciudad; la "Semana das Diferenças" promocionada por la Oficina de educación con la meta de divulgar lo trabajo de los profesores del Apoio Pedagógico Especial, sobre la propuesta de inclusión de las personas con deficiencia y; lo tercero evento del mes de agosto es lo "BC Prevenida", promocionado por la Oficina de Salud con la meta de informar a las personas sobre los cuidados con la salud. Los temas principales son: la salud de los mayores, salud oral, salud de la mujer, salud de los niños y sexualidad (PMBC, 2015).

Para septiembre los eventos son cuatro: la "Caminhada da Paz", un evento social que tiene como meta atraer a la comunidad para reunirse en las calles de la ciudad; los "Jogos JEBEQUINHO", uno de las etapas de las competiciones deportistas de las escuelas de la ciudad; la celebración del Dia Internacional do Turismo y lo evento más importante del mes, lo $8^{\circ}$ "Festival Náutico Marina Tedesco". Ese evento tiene la duración de una semana, cuenta con la presencia de los principales clubes náuticos brasileños para la exposición y negociación de equipamientos náuticos y embarcaciones. Además, lo evento también ofrece clases con temas náuticos. En 2014, lo evento recibió acerca de 10 mil visitantes y generó aproximadamente 10 millones de euros en negociaciones (MARINA TEDESCO, 2015).

El mes de octubre, aunque todavía no es un mes en el verano, no apuntan a una tendencia en la recepción de eventos locales, ya que es el mes de las fiestas en el estado de Santa Catarina. Por lo tanto, como se ha señalado antes, sobre el flujo mensual de los turistas, la ciudad de Balneário Camboriú es elegida por muchos turistas como lugar de alojamiento de los que van a ciudades como Blumenau, Itajaí o Brusque para visitar sus principales fiestas tradicionales, como ya se ha explicado. Así, en octubre no hay 
eventos muy grandiosos en el calendario de Balneário Camboriú, hay la celebración del "Outubro Rosa", un evento de concientización por la prevención del cáncer de mama en las mujeres. Por lo día de los niños, hay en Balneário Camboriú actividades como teatros, juegos y shows para lo público infantil durante todo un final de semana. Y hay también, los “Jogos de Integração JICIG", evento deportivo de pequeño porte de las escuelas locales.

El mes de noviembre de 2015 tiene sólo dos eventos programados: "Novembro Azul" y "Abertura dos Brilhos de Natal". Tal vez porque es un mes con fechas festivas ${ }^{10}$ en Brasil no es tan necesaria una agenda con muchos eventos para estimular una mayor demanda de turistas. El "Novembro Azul", es un evento en Brasil que alerta a los hombres a la importancia del diagnóstico precoz del cáncer de próstata y la "Abertura dos Brilhos de Natal" es la conmemoración del día en que se encienden las luces de navidad en la ciudad. Estas luces permanecen encendidas todas las noches hasta el 6 de enero Día del Reys.

Por último, el mes de diciembre, el primer mes de las vacaciones de verano brasileño, de las vacaciones escolares y de las fiestas de final de año (Navidad y Noche Vieja). Solamente esas fechas, son responsables por la gran concentración de flujo turístico en la ciudad. Por eso, eligen una fecha para celebrar la "Abertura da Temporada", que es la temporada de verano y el "Reveillón Show", la celebración de la Noche Vieja con espectáculos de música.

Balneário Camboriú posee una ubicación regional favorable, en el centro de una región con muchos atractivos (Parque Temático Beto Carrero, Oktoberfest) y cerca de ciudades con fuerte desarrollo económico y industrial (Itajaí y Joinvile). Por la presentación de la diversidad de los eventos, se debe considerar que muchos de esos destinos, principalmente los más cercanos, más que competir con Balneário Camboriú complementan su oferta. Muchos turistas se quedan hospedados en Balneário Camboriú y visitan los otros destinos durante el día. Lo mismo passa con las demás playas cercanas que posibilitan que el turista vaya por el día y regrese por la noche. BC tiene la ventaja de poseer una mayor oferta hotelera que las demás ciudades (SOARES, 2012).

Por los datos presentados registrase que hay una gran diversificación de los eventos en Balneário Camboriú, no solo por los segmentos como por el porte del evento y su duración, como por ejemplo: eventos sociales, de salud, deportivos, culturales, gastronómicos y otros. Vale señalar que la existencia de eventos que ocurren en un período durante el mes, no sólo en un día específico, son capaces de atraer turistas para alojarse en los hoteles de la ciudad, incrementando la ocupación en meses de temporada baja, contribuyendo para a minimización de la estacionalidad.

\section{CONCLUSIONES}

En este artículo hemos visto que Balneário Camboriú es una ciudad que se destaca por ser fundamentalmente turística y que crece en torno al desarrollo de dicha actividad. Este artículo ha presentado el problema de la estacionalidad en la ciudad centrada en el

10 El dia 2 de noviembre es el dia de los muertos y el 15 de noviembre es la Proclamación de la República. 
turismo de sol y playa, que ahora intenta desarrollar estrategias de diversificación turística a base de implementar el turismo de eventos y conseguir una mejor distribución de la oferta durante todo el año minimizando la estacionalidad.

En el caso de los eventos, en Balneário Camboriú tiene, entre otros, eventos de larga duración tales como festivales gastronómicos, el festival de cine y el festival náutico. Además, los eventos académicos se justifican en el calendario, sobre todo, por la presencia de un campus de la Universidad de Vale do Itajaí, en la ciudad y otro en la ciudad de Itajaí, distante a sólo $15 \mathrm{~km}$. La presencia de la universidad en la ciudad y en las cercanías de Itajaí es responsable de mantener una constante dinámica académica durante el período del año que, en cierto modo, influye en el equilibrio de la demanda de las vacaciones escolares, cuando estos estudiantes a menudo regresan a sus ciudades de origen y la ciudad de Balneário Camboriú recibe una nueva demanda de la época de vacaciones de verano en Brasil que están en el período comprendido entre los meses de diciembre a mes de febrero.

Hemos visto que la celebración de los eventos promueve permanecer un mayor número de días en la ciudad lo que repercute en el incremento de gasto y consumo de diversos elementos relacionados con el turismo: como son el alojamiento, la restauración, el gasto comercial, los servicios en general y la posibilidad de conocer y disfrutar de los atractivos turísticos de la ciudad. Además, la amplia oferta turística y la infraestructura complementaria ofrecida por Balneário Camboriú (alojamiento, servicios de comida, compras, ocio y entretenimiento) asociado con la configuración de una ciudad donde los servicios están relativamente cerca y concentrados, da a la ciudad junto con su centralidad geográfica en la región, una posición estratégica para estructurarse como centro de distribución de acceso a destinos turísticos con atractivos culturales, folclóricos, de naturaleza, patrimoniales, históricos y de negocios, entre otros.

No hay datos disponibles que muestran el número de turistas de los eventos de la ciudad, pero la dinámica de la distribución en el calendario anual es indicativo. Para futuras investigaciones, se buscarán los datos numéricos para dicha certificación. Así, llegamos a la conclusión de que la complementariedad de las actividades de los diversos segmentos turísticos entre las ciudades cercanas y la distribución de los eventos durante los meses del año que no son considerados la alta temporada, son las principales estrategias para diversificar la oferta turística en Balneário Camboriú.

\section{REFERENCIAS BIBLIOGRÁFICAS}

ALLCOCK, J. B. (1989): «Seasonality», en WITT, S; MOUTINHO, L. (Ed.), Tourism Marketing and Management Handbook Hertfordshire, Prentice Hall International, pp. 92-104

AYALA, H., MARTÍN, R., MASIQUES, J. (2003). «El turismo de sol y playa en el Siglo XXI», en Convención de Turismo de Cuba, XXIII. Varadero: Ministerio de Turismo.

BARON, R.R.V. (1975): Seasonality in Tourism: a guide to analysis of seasonality. Technical Paper n. 2. Economist Intelligence Unit.

BAUM, T.; HAGEN, L. (1999): «Responses to seasonality: The experiences of peripheral destinations», Journal of Tourism Research, vol.4, n. 01, pp. 299-312.

BAUM, T.; LUNDTORP, S. (2001): Seasonality in Tourism. Oxford, Pergamont. 
BORBA CORRÊA, I. (1985): História de duas ciudades: Camboriú e Balneário Camboriú. Balneário Camboriú, Edição do Autor.

BUTLER, R.W. (1994): «Seasonality in Tourism: issues and problems», en SEATON, A.V. ET AL. (Ed.), Tourism: The State of the art. Chichester, Wiley, pp. 332-339.

BUTLER, R.W. (2001): «Seasonality in Tourism: issues and implications», en BAUM, T., LUNDTORP, S., Seasonality in tourism, Oxford, Pergamont, pp. 5-21.

CANANI, I. S. S. (2001): «A comunicação em língua espanhola entre turistas e prestadores de serviços na hotelaria: região turística de Balneário Camboriú», Revista Turismo Visão e Ação, vol.4, n 08, pp. 119-123.

CLUBE DOS ENTAS ITAJAÍ (2015). Disponible en: <http://clubedosentasitajai.blogspot. com.es/>.

DÍEZ, D. (2012): «La competitividad turística en espacios interiores: una propuesta metodológica para la determinación de competidores potenciales», Cuadernos de Turismo, $\mathrm{n}^{\circ} 30$, pp. 109-125.

FUNDAÇÃO MUNICIPAL DE ESPORTE DE BALNEÁRIO CAMBORIÚ (2015). Disponible en: <http://www.fmebc.sc.gov.br/2015/03/31/maior-evento-de-beach-tennisdo-brasil-agitou-as-areias-de-bc/>.

GOOGLE MAPS (2015): Mapa de Localização Balneário Camburiú. Disponible en $<$ https://www.google.com.br/maps/place/Balne\%C3\%A1rio + Cambori \%C3\% BA++SC /@27.0058747,48.6169839,12z/data=!3m1!4b1!4m2!3m1!1s0x94d8 b65cc2e52a ad:0x2dc004f5e6adebc4?hl=pt-BR>.

INOSTROSA, G; CÀNOVES, G. (2014): «Turismo sostenible y proyectos hidroeléctricos: contradicciones en la Patagonia chilena», Cuadernos de Turismo, $\mathrm{n}^{\circ} 34$, pp. 115-138.

INSTITUTO BRASILEIRO DE GEOGRAFIA ESTATÍSTICA (IBGE) (2014): Cidades. Disponible en: $<$ http://cidades.ibge.gov.br/ xtras/perfil.php?lang=\&codmun=420200\& search $=$ santa-catarinalbalneario-camboriu $>$.

KOENIG, N.; BISCHOFF, E. (2004): «Seasonality Research: The State of the Art», International Journal of Tourism Research, $\mathrm{n}^{\mathrm{o}}$ 7, pp.201-219.

LAGE, H. G.; MILONE, P. C. (1998): Economia do turismo. Campinas, Papirus.

MARINA TEDESCO (2015). Disponible en: <http://tedescomarina.com.br/>.

MINISTERIO DO TURISMO (MTur) (2008): Estudo de Competitividade dos 65 Destinos Indutores do Desenvolvimento Turístico Regional, Relatório Brasil, $2^{\mathrm{a}}$ ed. Revisada. Brasília, Ministério do Turismo.

MINISTERIO DO TURISMO (MTur) (2011): Estudo da demanda turística internacional 2004 - 2010. Disponible en: <http://www.dadosefatos.turismo.gov.br/export/ sites/default/dadosefatos/demanda_turistica/internacional/download_internacional/ Demanda_Turxstica_Internacional_-_Fichas_Sinteses_-_2004-2010.pdf>.

MINISTERIO DO TURISMO (MTur) (2013): Índice de competitividade do turismo nacional: destinos indutores do desenvolvimento turístico regional, Relatório Brasil 2013. Brasília, Ministério do Turismo.

MINISTERIO DO TURISMO (MTur) (2015): Anuário Estatístico de Turismo, vol. 42. Disponible en: < http://www.turismo.gov.br/images/pdf/anuario_estatistico_de_ turismo_2015_ano_base_2014_pdf.pdf>. 
NEVES, H.; CRUZ, A. R.; CORREA, A. (2007): «A sazonalidade da procura turística na ilha de Porto Santo», Revista Portuguesa de Estudos Regionais, n ${ }^{\circ} 17$, pp. 25-44.

PELLIZZONI, L. R. C. (2004): A imagem das destinações turísticas: estudo de caso Balneário Camboriú, Tesis de Maestria (Inédita), Universidade do Vale do Itajaí, Balneário Camboriú.

PREFEITURA MUNICIPAL DE BOMBINHAS (2015): Disponible em: <http://turismo. bombinhas.sc.gov.br/>.

PREFEITURA MUNICIPAL DE BALNEÁRIO CAMBORIÚ (PMBC) (2014): Leis Municipais. Disponible en: < https://www.leismunicipais.com.br/legislacao-munici$\mathrm{pal} / 4511 /$ leis-de-balneario-camboriu> .

PREFEITURA MUNICIPAL DE BALNEÁRIO CAMBORIÚ (PMBC) (2015): Disponible en: <http://www.balneariocamboriu.sc.gov.br/imprensa/noticia.cfm?codigo=13540>.

PREFEITURA MUNICIPAL DE CAMBORIÚ (2015): Disponible en: <http://www.turismocamboriu.com.br/camboriu/>.

PREFEITURA MUNICIPAL DE ITAJAÍ (2015): Disponible en <http://www.itajai.sc.gov. br/>.

RAMÍS, M. A. C; LLINÁS, M. S. (2014): «El papel del clima en la estacionalidad turística y la configuración de productos turísticos emergente: El caso de Mallorca», Cuadernos de turismo, $\mathrm{n}^{\mathrm{o}} 33$, pp. 15-30.

RAMOS, D. R. (2009): A invenção da praia e a produção do espaço: dinâmicas de uso e ocupação do litoral do Espírito Santo, Tesis de Maestria (Inédita), Universidade Federal do Espírito Santo, Vitória.

RUSCHMANN, D. (1997): Marketing Turístico: um enfoque promocional. Campinas, Papirus.

SANCHO, A. (1998): Introducción al turismo. Organização Mundial del Turismo.

SANTA CATARINA TURISMO (SANTUR) (2014). Disponible en: <http://turismo. sc.gov.br/>.

SANTA CATARINA TURISMO (SANTUR) (2015). Disponible en: < http://turismo. sc.gov.br/institucional/index.php/pt-br/>.

SANTOS PAVÓN, E. L. y FERNANDÉZ TABALES, A. (2010): «El litoral turístico español en la encrucijada: entre la renovación y el continuismo», Cuadernos de Turismo, $\mathrm{n}^{\mathrm{o}} 25$, pp.185-206.

SCHEUER, L. (2011): «Percepção geográfica e planejamento turístico: um estudo sobre a Sazonalidade», Turismo \& Sociedade. Curitiba, vol. 4, n², pp. 286-304.

SECRETARIA DE ESTADO DE TURISMO, CULTURA E ESPORTE (SOL) (2015). Disponible en: < http://www.sol.sc.gov.br/>.

SECRETARIA DE TURISMO DE BALNEÁRIO CAMBORIÚ (SECTURBC) (2010): Inventario de meios de hospedagem, restaurantes, bares e casas noturnas.

SECRETARIA DE TURISMO DE BALNEÁRIO CAMBORIÚ (SECTURBC) (2014): Programa de promoção do turismo catarinense ação: estudos e pesquisas de turismo. Disponible en: <http://www.secturbc.com.br/estatisticas/1343156374.pdf >.

SECRETARIA DE TURISMO DE BALNEÁRIO CAMBORIÚ (SECTURBC) (2015): Calendário de Eventos. Secretaria de turismo de Balneário Camboriú. Disponible en: <http://www.secturbc.com.br/tb2013/pt-br/eventos>. 
SERVIÇO BRASILEIRO DE APOIO A MICRO E PEQUINAS EMPRESAS (SEBRAE) (2010): Santa Catarina em números: Balneário Camboriú. SEBRAE, Florianópolis.

SILVA, G. A. (2002): Uso Turístico da Praia Central do município de Balneário Camboriú - SC: projeções técnico-científicas, Tesis de Maestria (Inédita), Universidade do Vale do Itajaí, Balneário Camboriú.

SILVEIRA JUNIOR, N. C. (1952): Álbum fotográfico descriptivo da Praia de Camboriú. Florianópolis, Gráfica 43.

SKALEE, M.; REIS, A. F. (2008): «Crescimento urbano turístico: traçado e permanências urbanas em Balneário Camboriú», en Colóquio Internacional de Geocrítica, X, mai. de 2008. Universidade de Barcelona. Disponible en: <http://www.ub.edu/geocrit/$\mathrm{xcol} / 184 . \mathrm{htm}>$.

SOARES, J. C. (2012): La evolución de los destinos turísticos litorales consolidados: Un análisis comparado de Balneario Camboriú (Brasil) y Benidorm (España), Tesis Doctoral, Universidad de Alicante, España.

STARKE LEE, M. (1998): Balneário Camboriú: desenvolvimento de uma cidade litorânea. Tesina de Máster en Geografía Humana, Universidad de São Paulo.

VALLS, J. (2004): Gestión de destinos turísticos sostenibles. España, ESIC, Gestión 2000.

VERA REBOLLO, J.F.; BAÑOS, C.L. (2010): «Renovación y reestructuración de los destinos turísticos consolidados del litoral: las prácticas recreativas en la evolución del espacio turístico», Boletín de la Asociación de Geógrafos Españoles, n. 53, pp. 329-353.

VERA REBOLLO, J. F., LÓPEZ PALOMEQUE, F., MARCHENA GÓMEZ, M., ANTÓN CLAVÉ, S. (1997): Análisis Territorial del Turismo. Barcelona, Ariel. 